\title{
Gerenciamento térmico da bateria em veículos elétricos: o sistema líquido combinado
}

\author{
Luis Alfredo Bufalo, Gabriel Morales Gonelli e Luis F. Baumgartner \\ MAHLE Behr Gerenciamento Térmica Ltda. \\ luis.bufalo@br.mahle.com, gabriel.a.gonelli@br.mahle.com, \\ luis.baumgartner@br.mahle.com
}

\section{RESUMO}

A principal fonte de energia para os veículos elétricos é a bateria Lítio-íon caracterizada por elevada densidade de potência, longa vida útil e possui menor impacto ambiental. No entanto, alguns fatores limitam o desenvolvimento da bateria, afetando especialmente desempenho, vida útil e segurança. Esses fatores em um veículo híbrido/elétrico são seguramente melhorados quando se dispõe de um sistema de gerenciamento térmico eficiente. Tal eficiência manifesta-se na capacidade de se manter o conjunto de baterias na faixa de temperatura ideal ao mesmo tempo em que não se demanda potência em excesso do sistema de alimentação que deveria abastecer o módulo de propulsão. Este trabalho apresenta o sistema líquido combinado onde o circuito refrigerante do ar-condicionado é derivado para um trocador adicional refrigerante-água denominado chiller, acoplado a uma segunda válvula de expansão que proporciona potencial de refrigeração para - circuito secundário (água) que por sua vez está conectado às placas de refrigeração do conjunto de baterias. Uma avaliação utilizando-se de critérios tais como maiores índices de performance, flexibilidade de utilização, segurança e eficiência energética indica os benefícios desta solução quando comparado a outros modelos.

\section{INTRODUÇÃO}

O uso de combustível fóssil continua sendo questionado em função de seu já conhecido impacto ambiental. Sob a ótica da mobilidade, os veículos elétricos (EV) e/ou híbridos (HEV e PHEV) colocam-se como alternativas para a redução dos gases do efeito estufa (GEE) [1]. A seriedade desta proposta pode ser avaliada nos objetivos estabelecidos até 2030 pelos órgãos internacionais, conforme projeções da figura 1. O EVI 2020 visa uma frota global de carros elétricos de 20 milhões até 2020 enquanto que a Declaração de Paris sobre a Mobilidade Elétrica e Mudanças Climáticas estabelece um objetivo de implantação global de 100 milhões de carros elétricos e 400 milhões de veículos de 2 ou 3 rodas em 2030. Além disso, dados da IEA 2DS (International Energy Agency 2 degree scenario) mostram que manter taxas de crescimento anual superiores a $25 \%$ até 2025 e na faixa de $7 \%$ a $10 \%$ entre 2030 e 2050, limitam em $2^{\circ} \mathrm{C}$ o aumento da temperatura global [2, 4]. 


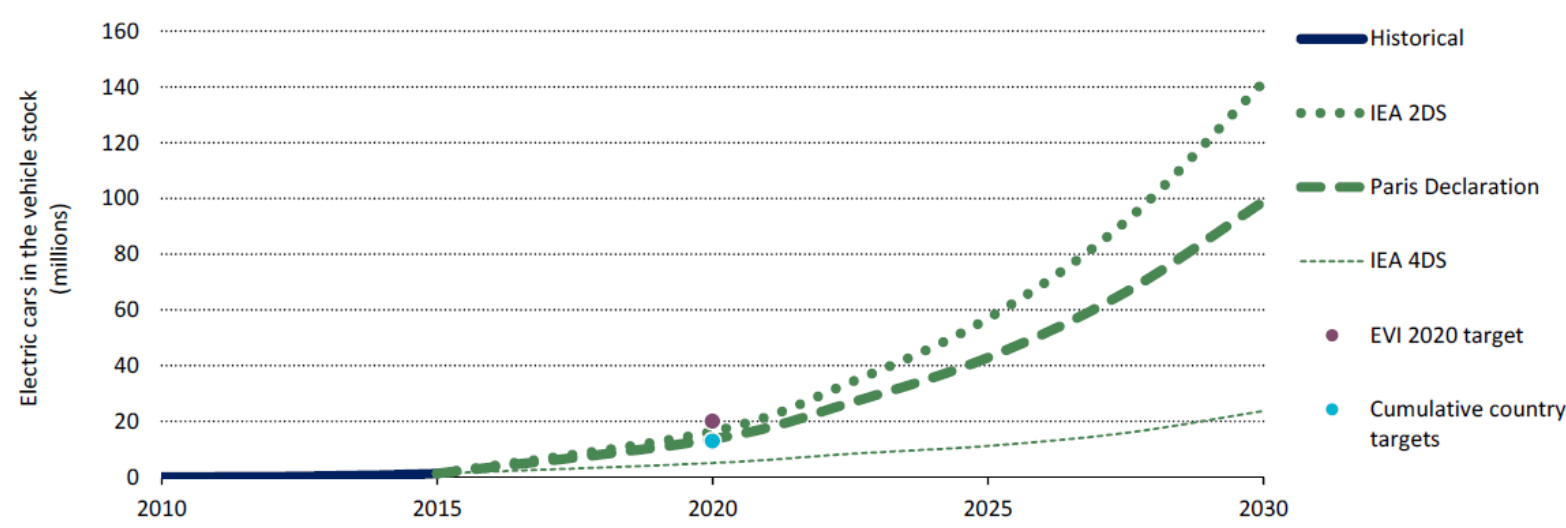

Figura 1: Projeção da frota de veículos elétricos até 2030 [4]

Vale ressaltar ainda que em países cuja matriz de produção de eletricidade esteja fortemente vinculada a óleo ou carvão, os veículos elétricos apresentam índices de emissões de $\mathrm{CO}_{2}$ menores quando comparados aos de combustão interna (ICE), mesmo considerando que serão obtidos indiscutíveis avanços tecnológicos nos motores convencionais até 2030 [3]. A figura 2 mostra um comparativo no nível de emissões de carbono em gramas de $\mathrm{CO}_{2}$ por milha percorrida para ICE e EV em países dependentes de fontes de energia elétrica geradas a carvão, como Reino Unido (UK), China e Estados Unidos (EUA).

$\mathrm{gCO}_{2} / \mathrm{milha}$
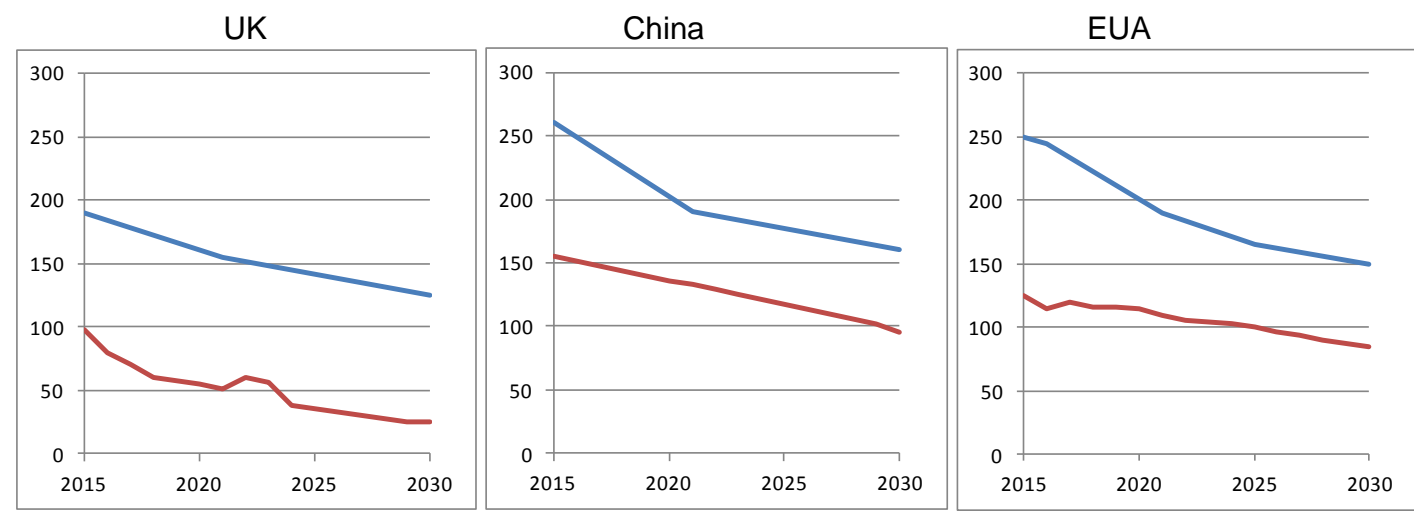

Figura 2: Média de emissões de diferentes motores [3]

Esse progresso inequívoco da manufatura de veículos elétricos/híbridos traz como efeitos de segunda ordem o aumento de escala na produção de baterias Li-ion e consequente redução do custo do material. Em 2008, a densidade de energia das baterias PHEV era de $60 \mathrm{Wh} / \mathrm{L}$ (Watts-hora/litro) enquanto que em 2015, esse número aumentou para $295 \mathrm{Wh} / \mathrm{L}$, melhoria de por volta de $400 \%$. Porém, para atingir a meta definida pelo Departamento de Energia dos Estados Unidos (US DOE) será necessário um adicional de $36 \%$ na densidade a ser alcançada nos próximos sete anos. Por outro lado, montadoras americanas preveem redução do custo na ordem de $90 \%$ do quando comparado ao número de 2008 que era de 1000 USD / kWh (dólares americados por kW hora) (figura 3) [4]. 


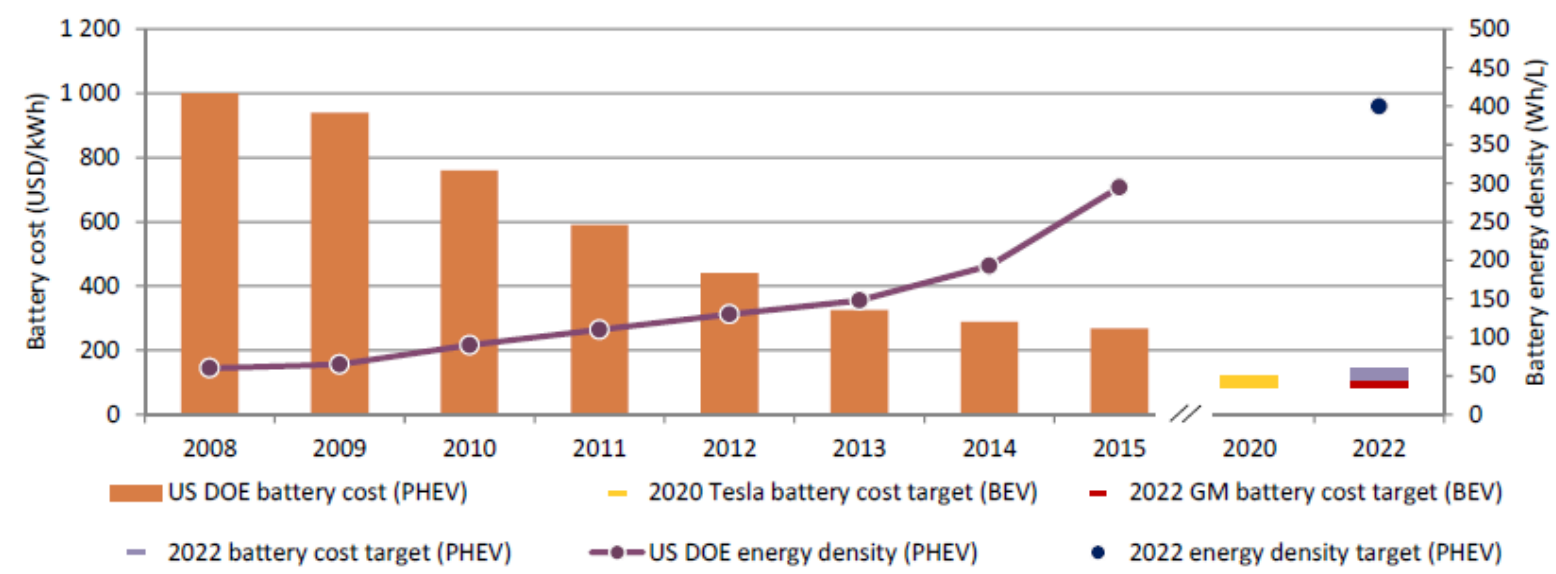

Figura 3: Evolução da densidade de energia da bateria e custo [4]

Esse movimento também incentiva novos desdobramentos tecnológicos no sentido de aumentar a diversidade de produção e consequentemente a autonomia dos veículos. A Tesla, por exemplo, oferece em seu site americano o Model S com opções de fontes de energia com garantia vitalícia, e potência que variam de 75 $\mathrm{kWh}$, com autonomia de $415 \mathrm{~km}$ e velocidade máxima de $225 \mathrm{~km} / \mathrm{h}$, a $100 \mathrm{kWh}$ que percorre $540 \mathrm{~km}$ em um carro com tração integral (referência de autonomia conforme Agência Americana de Proteção Ambiental) [5]. Com base nesses valores pode-se ter a dimensão da capacidade de armazenamento de energia deste tipo de bateria, que vem evoluindo consideravelmente desde 2008 conforme mostrado na figura 3 [4].

Entretanto, fatores chave para os consumidores como eficiência de armazenamento (diretamente correlacionada com a autonomia) e velocidade de recarga deste tipo de bateria dependem da faixa de temperatura de exposição, onde danos irreversíveis poderão ocorrer caso permaneçam além dos limites extremos por longos períodos. Para melhor aproveitamento das vantagens das baterias de lítio-ion torna-se necessário nos veículos elétricos um sistema de gerenciamento térmico capaz de manter a temperatura dentro das limitações ideais de projeto. [6]

Neste trabalho serão apresentadas as tecnologias atualmente existentes no gerenciamento térmico da bateria, explicando de forma sucinta por meio de ilustrações o funcionamento de cada uma delas que permitirá a comparação desses sistemas através de uma tabela com parâmetros de referência, os mais eficazes para aplicação em veículos elétricos e híbridos.

\section{A BATERIA LÍTIO-ÍON - PROBLEMAS E REQUISITOS OPERACIONAIS}

\subsection{Problemas}

O principal fator limitante ao desenvolvimento da bateria, afetando especialmente desempenho, vida útil e segurança, que deve ser controlado cuidadosamente é a temperatura de trabalho, pois tanto o excesso quanto a falta de calor poderão ocasionar diferentes problemas.

Em temperaturas abaixo da ideal, ocorrerá uma diminuição na taxa de reação química da bateria, pois essas taxas possuem relação linear com a 
temperatura, e redução da capacidade de transportar corrente durante a carga e descarga. Além disso, a redução da taxa de reação torna mais difícil inserir íons de lítio em espaços de intercalação. O resultado é a redução de potência e do revestimento de lítio causando a perda de capacidade de armazenagem de carga [7].

Em contrapartida, alta temperatura aumenta a taxa de reação gerando cada vez mais potência. No entanto, essa alta taxa de reação também aumenta a dissipação de calor e gera temperaturas ainda mais elevadas. A menos que 0 calor seja dissipado mais rapidamente do que ele é gerado, a temperatura será cada vez maior até o ponto que poderá ocorrer danos irreversíveis ou até mesmo o curto circuito da bateria [7].

\subsection{Requisitos operacionais}

Como já foi dito, a temperatura da bateria deve ser controlada para evitar diversos problemas térmicos, melhorar sua vida útil e performance. As figuras 4 e 5 mostram a interação da temperatura com a potência e o ciclo de vida da bateria. Observa-se na figura 4 que a curva de potência da bateria alcança seu ponto máximo entre $20^{\circ} \mathrm{C}$ e $40^{\circ} \mathrm{C}$.

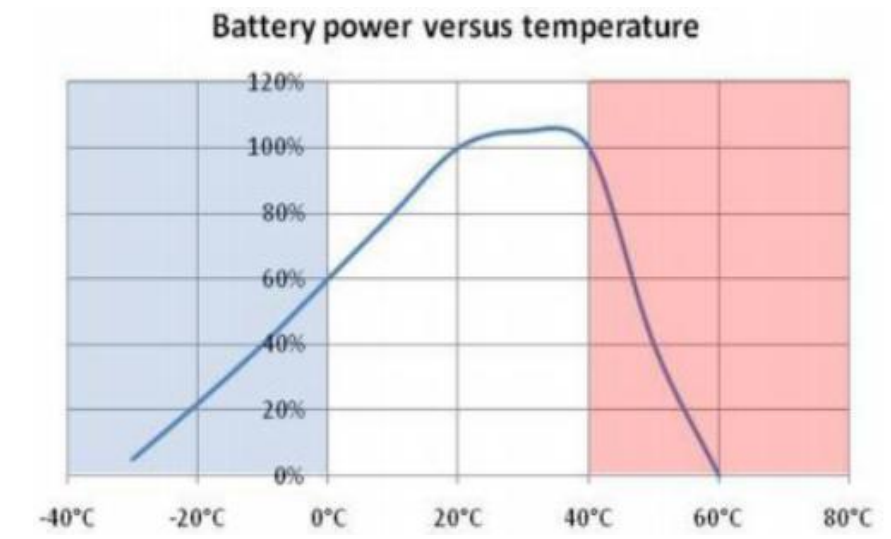

Figura 4: Integração da temperatura com a potência da bateria [8]

$\mathrm{Na}$ figura 5 nota-se que o ciclo de vida da bateria se mantém estável entre as temperaturas de $10^{\circ} \mathrm{C}$ a $60^{\circ} \mathrm{C}$.

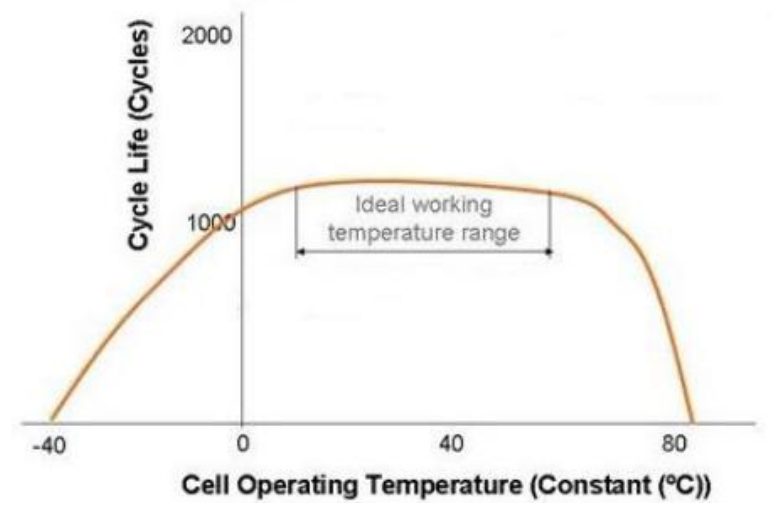

Figura 5: Integração da temperatura com o ciclo de vida da bateria [7] 
Sendo assim, um gerenciamento térmico da bateria é necessário para se manter a temperatura geralmente entre $20{ }^{\circ} \mathrm{C}$ e $40 \stackrel{\circ}{\circ}$, podendo haver alterações em caso de diferentes composições das baterias. Além disso, a distribuição de temperatura deve ser mantida em um alcance de até $5 \mathrm{~K}$ para manter-se a segurança e vida útil [9].

\section{TECNOLOGIAS DE GERENCIAMENTO TÉRMICO DA BATERIA}

O objetivo de um sistema de gerenciamento térmico é entregar uma bateria com uma temperatura média otimizada, tendo em vista a vida útil e o desempenho (tanto de potência quanto de capacidade), com distribuição uniforme, aceitando pequenas variações entre o sistema e a bateria, tal como identificado pelo fabricante. Entretanto, o sistema de gestão térmica tem de satisfazer os requisitos do veículo, também especificados pelo fabricante. Este deve ser compacto, leve, de baixo custo e compatível com a localização no veículo. De acordo com estudos realizados [9], o BTMS deve possuir quatro funções fundamentais para proporcionar as condições de operação ideais da bateria.

A primeira delas é o arrefecimento. Devido à ineficiência, as células de bateria irão gerar, além da eletricidade, calor. Este deve ser movido da bateria quando a temperatura ideal é atingida ou mesmo com antecedência para se evitar danos ao sistema.

Outra função necessária é o aquecimento. Em climas frios, a temperatura da bateria provavelmente cairá abaixo do limite de temperatura especificado. Consequentemente, é necessária uma função de aquecimento para auxiliar a bateria a atingir a temperatura adequada em um curto período de tempo, evitando-se danos irreversíveis.

Em climas frios ou quentes extremos, a diferença de temperatura entre o interior e $o$ exterior da bateria é muito maior do que em climas amenos. A temperatura da bateria irá cair, caso se esteja frio, ou subir, caso se esteja quente, mais cedo para fora da faixa de temperatura adequada. Para evitar isso, bom isolamento pode diminuir a queda ou aumento da temperatura da bateria.

Por último, a ventilação é necessária para expulsar os eventuais gases perigosos de dentro da bateria.

\subsection{Sistema de ar forçado passivo}

O sistema de ar forçado passivo é assim chamado pois recebe ar diretamente da cabine/atmosfera e é impulsionado através do motor para o sistema da bateria. A figura 6 demonstra o esquema.

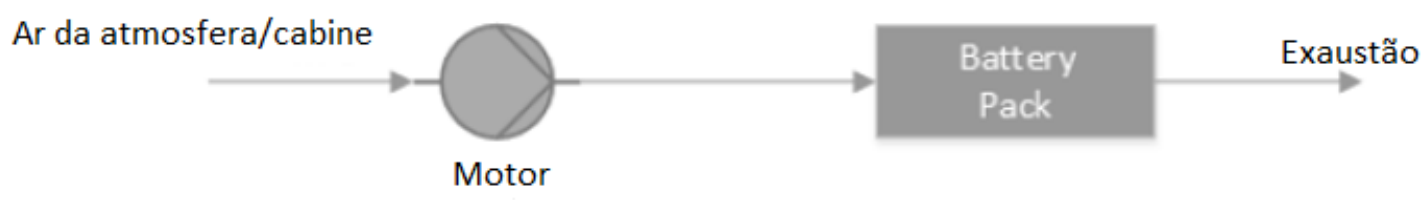

Figura 6: Layout do sistema de ar forçado passivo 
Esse sistema possui uma estrutura simples, com custo baixo, fácil manutenção e performance de baixa eficiência. Por depender diretamente da temperatura do ar ambiente, o sistema não consegue manter a uniformidade na distribuição de temperatura, podendo ocorrer danos irreversíveis na bateria em casos extremos [10].

\subsection{Sistema de ar forçado ativo}

O sistema de ar forçado ativo utiliza o ar admitido após ter passado pelo aquecedor ou evaporador do sistema de ar condicionado. A figura 7 demonstra o sistema.

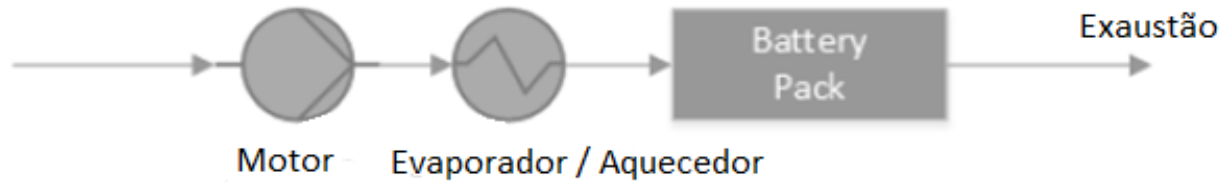

Figura 7: Layout do sistema de ar forçado ativo.

Comparando ao sistema de ar passivo, ambos possuem estrutura simples, com custo baixo e de fácil manutenção, e performance de baixa eficiência pelos motivos já mostrados. Entretanto, o sistema ativo oferece maior potência de arrefecimento ou aquecimento.

Em ambos os circuitos não é necessário a construção adicional de um ventilador, pois eles oferecem todas as funções necessárias de aquecimento, arrefecimento e ventilação mostradas anteriormente, entretanto observa-se que $o$ ar de exaustão não retorna a cabine.

\subsection{Sistema de ar forçado com recuperação de calor}

Em alguns casos, uma unidade de recuperação de calor (trocador de calor arar) é montada após a bateria para recuperar o calor do ar de exaustão. Ele pode evitar a mistura de ar de exaustão com ar de admissão e ao mesmo tempo fornecer um potencial de economia extra. O sistema de ar forçado com recuperação de calor é apresentado na figura 8.

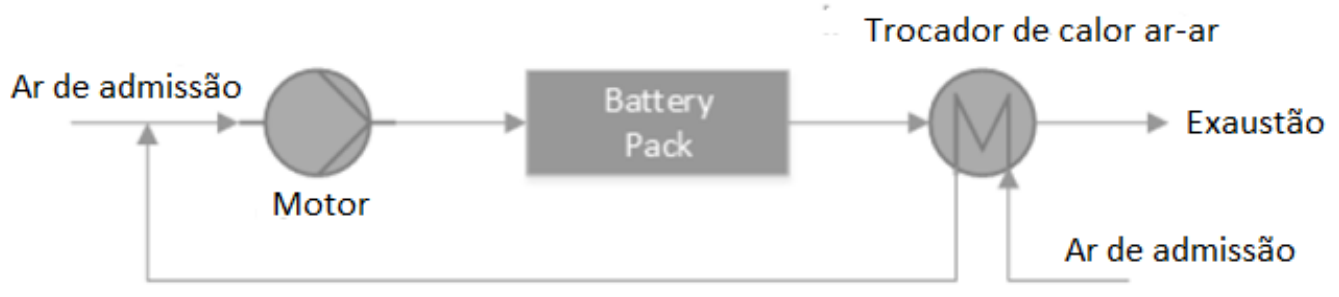

Figura 8: Layout do sistema de ar forçado com recuperação de calor. 


\subsection{Sistema líquido}

Há dois grupos de líquido diferentes que podem ser utilizados para o gerenciamento térmico do sistema da bateria. O primeiro deles é o que pode entrar em contato direto com as células da bateria, chamado de dielétrico. $O$ outro possui contato indireto com as células da bateria, conhecido como líquido condutor. Diferentes layouts são projetados dependentemente do tipo de líquido escolhido. Para o líquido de contato direto, um sistema que submerge o conjunto da bateria é montado. Para o líquido de contato indireto, um possível layout pode ser um invólucro ao redor do módulo da bateria, tubulação discreta em torno de cada módulo, colocando os módulos da bateria na placa de resfriamento / aquecimento ou combinando o módulo da bateria com as placas e resfriamento / aquecimento. Entre esses dois grupos, preferem-se os sistemas de contato indireto, a fim de obter um melhor isolamento entre o módulo da bateria e o ambiente e, portanto, um melhor desempenho de segurança [11].

\subsubsection{Sistema liquido passivo}

O sistema liquido passivo é assim chamado pois o dissipador de calor utilizado é um radiador, não tendo capacidade de aquecimento. A figura 9 mostra o sistema. O fluído é impulsionado pela bomba no interior de um sistema fechado. O calor absorvido pelo fluído ao passar pelo conjunto da bateria é dissipado através do radiador. Esse sistema é limitado pois depende fortemente da temperatura externa, sendo que se a do ar ambiente for superior a temperatura do modulo da bateria ou a diferença entre elas for pequena, a potência de resfriamento será muito baixa, tornando o sistema líquido passivo ineficiente [11].

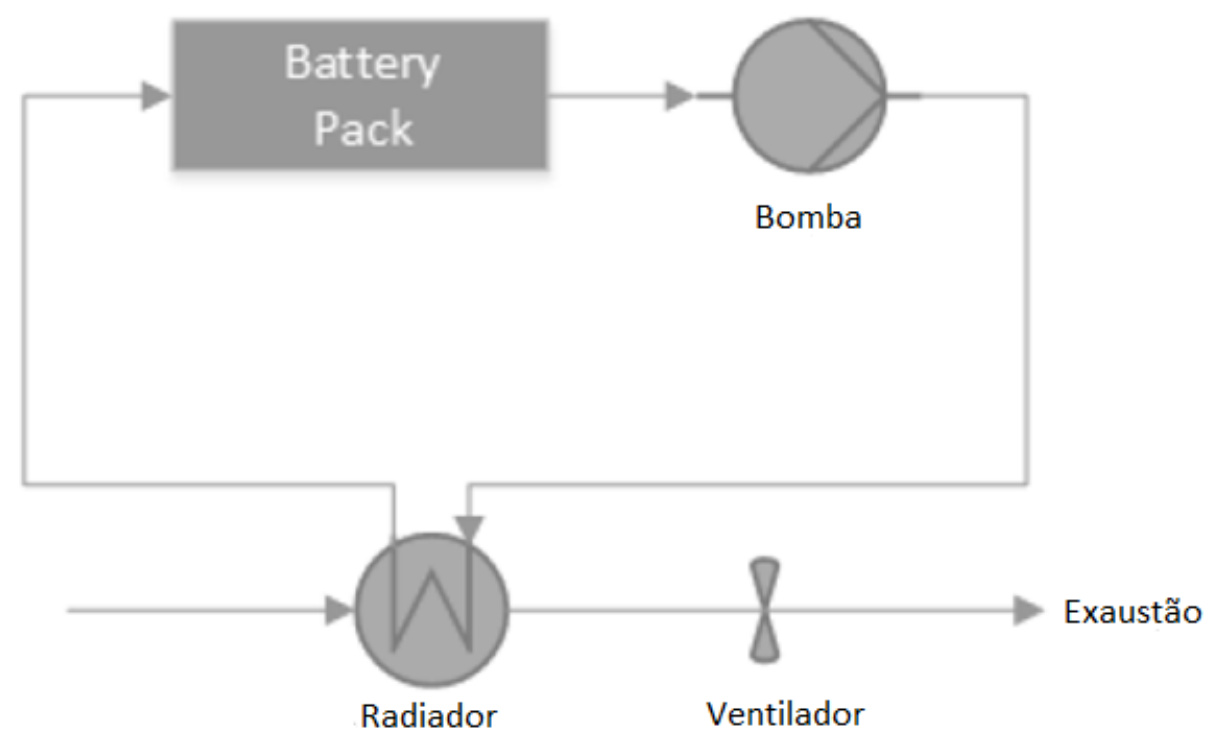

Figura 9: Layout do sistema liquido passivo. 


\subsubsection{Sistema liquido ativo}

O sistema liquido ativo possui dois loops, conhecidos como ciclo primário (superior) e ciclo secundário (inferior). O ciclo primário é semelhante ao sistema líquido passivo, onde a diferença está no dissipador de calor. O ciclo secundário é o loop do ar condicionado, sendo que a ligação entre os dois ciclos é feita através do evaporador que trabalha como agente de arrefecimento. Para o caso da necessidade de aquecimento, a válvula de quatro vias é acionada e o trocador de calor superior passa a ser utilizado como um condensador, enquanto o inferior trabalha como um evaporador. Apesar do sistema ser muito mais eficiente se comparado ao passivo, a estrutura é muito mais complexa e a dificuldade de manutenção é elevada $[10,11]$. O layout do sistema encontra-se na figura 10.

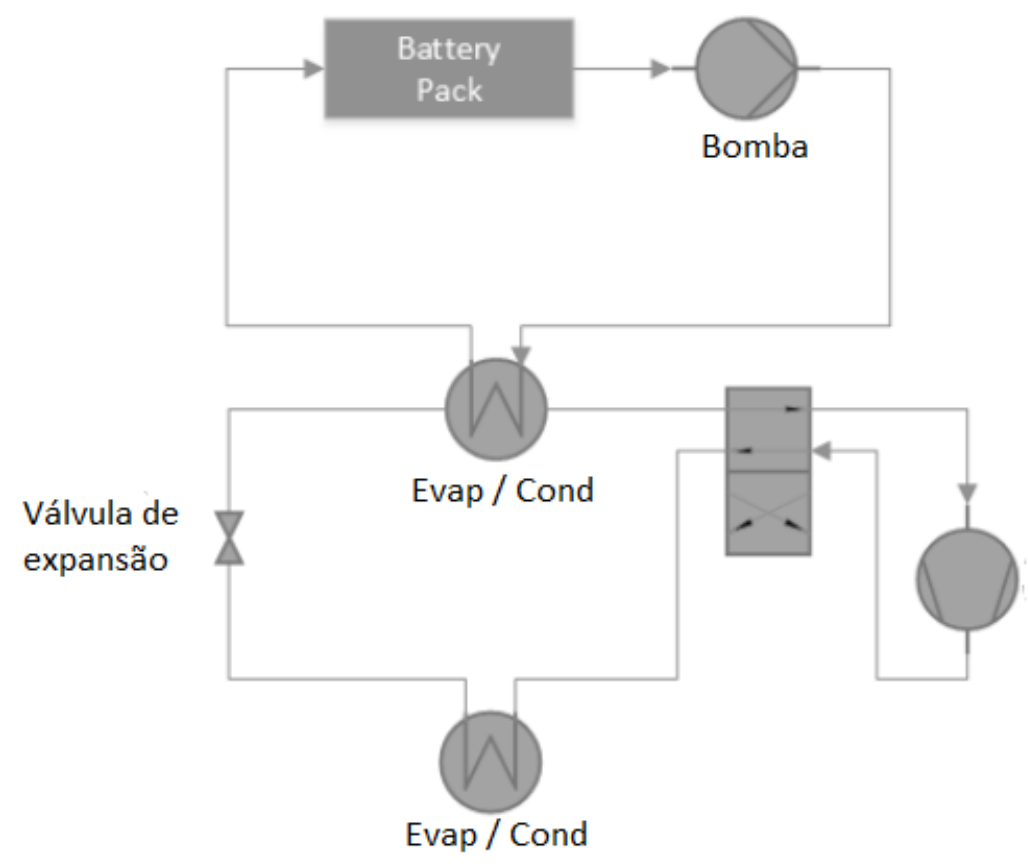

Figura 10: Layout do sistema liquido ativo.

\subsubsection{Sistema de arrefecimento e aquecimento direto por refrigerante}

O sistema de arrefecimento e aquecimento direto por refrigerante é semelhante ao sistema líquido direto. Utilizando-se apenas do loop do ar condicionado, o refrigerante é circulado diretamente pelo conjunto da bateria resfriando-a ou aquecendo-a, dependendo da ativação da válvula de quatro vias. Comparado aos sistemas líquidos, esse sistema é mais simples estruturalmente devido ao fato do refrigerante resfriar a bateria diretamente e, além disso, sua eficiência é maior. Entretanto os problemas de complexidade estrutural e dificuldade de manutenção continuam. O sistema é mostrado na figura 11. 


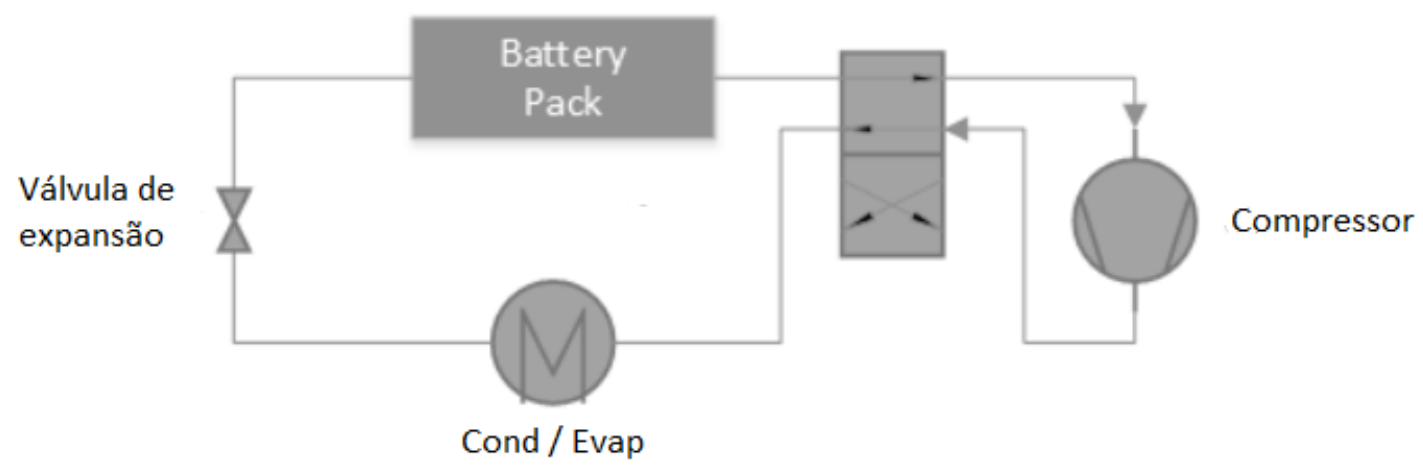

Figura 11: Layout do sistema de arrefecimento e aquecimento direto por refrigerante.

\subsubsection{Sistema líquido combinado}

Conforme demonstrado na figura 12, o sistema líquido combinado opera em quatro modos: circulação de líquido sem funcionamento do chiller quando a temperatura da bateria já encontra-se na faixa ideal de funcionamento; circulação com funcionamento do chiller como aquecedor, visando aumentar a temperatura de trabalho da bateria até seu nível adequado; circulação com funcionamento do chiller como resfriador (ativo), atuando em conjunto com o sistema de ar condicionado visando resfriar a bateria quando em temperaturas elevadas; por último passagem apenas pelo radiador de baixa temperatura (passivo) com o objetivo de resfriar a bateria quando em temperaturas moderadas. $O$ sistema de resfriamento passivo tem estrutura simples e é capaz de dissipar o calor em condições normais com baixo consumo de energia. Em condições extremas, o sistema de arrefecimento ativo tem bom desempenho térmico para manter a temperatura da bateria na faixa desejada. Apesar de o sistema ser robusto e possuir alto desempenho térmico, a complexidade estrutural e manutenção exigidas são ainda maiores quando comparados com os sistemas apresentados anteriormente. 


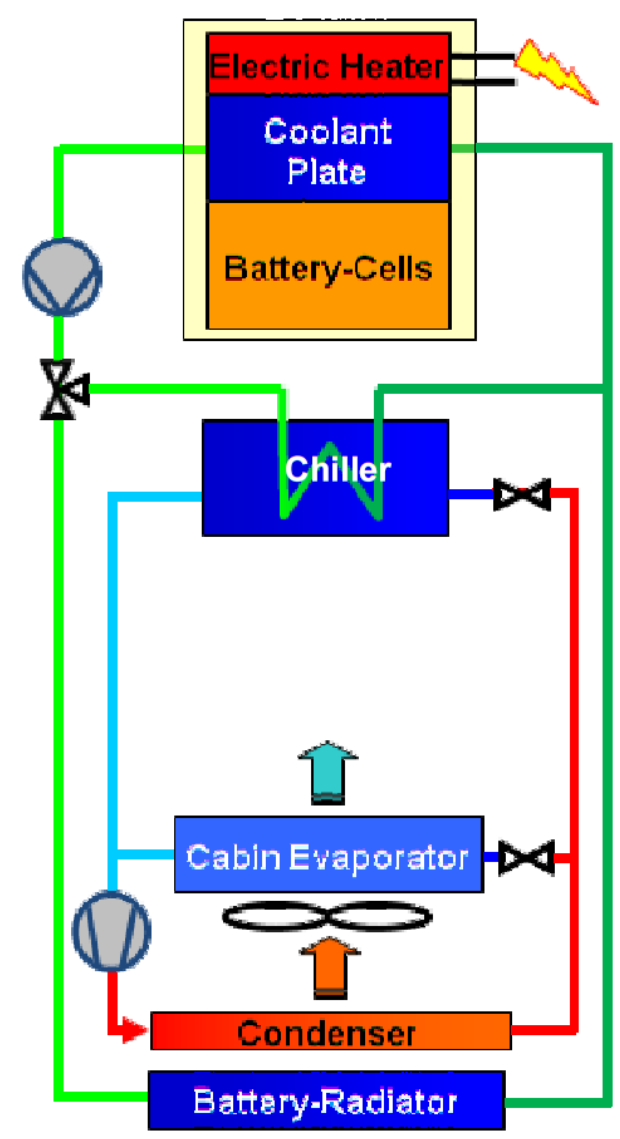

Figura 12: Layout do sistema de arrefecimento e aquecimento direto por refrigerante.

\section{METODOLOGIA E RESULTADOS}

Foram apresentados diversos tipos de sistemas de arrefecimento de baterias desenvolvidos até hoje e as principais particularidades de cada um deles, de modo que pudemos observar vantagens e desvantagens. Dessa forma, para um melhor método de avaliação dos resultados serão apresentados, através de uma matriz de decisão, a comparação para cada critério avaliado.

Essa matriz permite uma rápida análise através de critérios que favorecem uma visão mais ampla e coerente de alternativas. Apesar de trabalhar subjetivamente, ela servirá como um guia para encontrar tendências que se enquadram melhor à nossa realidade. Ela também auxilia na identificação de pontos fortes e fracos de cada proposta, tornado mais simples a escolha para um próximo projeto. [11]

Com o intuito de decidir qual dos sistemas é mais vantajoso, foi feita uma matriz de decisão com os seguintes parâmetros: índices de performance, flexibilidade de utilização, segurança, consumo energética, peso e custo.

A escala escolhida para avaliar o peso de cada parâmetro foi de 1, 3, 6, 10 e 12 e a intercorrelação parâmetro-sistema 1, 3 e 9 . Por meio do produto da matriz, será possível determinar de uma forma quantitativa qual o melhor sistema de gerenciamento térmico disponível no mercado para aplicação em veículos híbridos e elétricos. 
Apesar de todos os parâmetros terem a sua importância, alguns são mais relevantes, tendo assim uma diferença entre as suas escalas explicadas a seguir com base em suas influências.

circuito.

Performance (12): Nível de eficiência de refrigeração/aquecimento do - $\quad$ Segurança (10): Capacidade de se evitar variações de temperatura fora das condições ideais, evitando-se mal funcionamente da bateria e, em casos extremos, danificação do sistema.

- Peso (6): Quanto maior a massa do sistema, maior será os custos e consumo do veículo.

- $\quad$ Custo (3): Custo total do sistema, quanto maior o valor da intercorrelação, menor o custo.

- $\quad$ Consumo energético (3): Nível de demanda energética do sistema.

- $\quad$ Flexibilização de utilização (1): Capacidade de se utilizar o sistema em diferentes tipos de veículo mantendo-se os requisitos mínimos de funcionamento da bateria.

A seguir é apresentada a matriz de decisão com os parâmetros anteriormente mostrados.

Tabela 1: Matriz de decisão sistema de gerenciamento térmico da bateria

\begin{tabular}{|c|c|c|c|c|c|c|c|c|}
\hline \multicolumn{2}{|r|}{ Peso dos fatores } & 1 & 3 & 3 & 6 & 10 & 12 & \multirow[b]{2}{*}{ Total } \\
\hline Parâmetros & Critérios & $\begin{array}{l}\text { Flexibilização } \\
\text { de Utilização }\end{array}$ & $\begin{array}{r}\text { Consumo } \\
\text { Energético }\end{array}$ & Custo & Peso & Segurança & Performance & \\
\hline \multirow{3}{*}{$\mathrm{Ar}$} & Sistema de Ar Forçado Passivo & 1 & 9 & 9 & 9 & 1 & 1 & 131 \\
\hline & Sistema de Ar Forçado Ativo & 1 & 9 & 9 & 9 & 1 & 3 & 155 \\
\hline & \begin{tabular}{|l|} 
Sistema de Ar Forçado Com \\
Recuperação de Calor \\
\end{tabular} & 1 & 9 & 9 & 9 & 1 & 3 & 155 \\
\hline \multirow{3}{*}{ Líquido } & Sistema Líquido Passivo & 3 & 9 & 3 & 3 & 3 & 3 & 123 \\
\hline & Sistema Líquido Ativo & 9 & 1 & 3 & 1 & 3 & 9 & 165 \\
\hline & Sistema Líquido Combinado & 9 & 1 & 1 & 1 & 9 & 9 & 219 \\
\hline Refrigerante & Sistema Direto por Refrigerante & 9 & 1 & 3 & 3 & 3 & 9 & 177 \\
\hline
\end{tabular}

\section{CONCLUSÃO}

Os veículos elétricos exigem um sistema de gerenciamento térmico da bateria eficiente para permitir a operação em climas adversos. $O$ projeto da disposição deste sistema tem um impacto positivo na gestão térmica da bateria e seu comportamento. Um BTMS que usa o ar como meio de transferência de calor é mais simples, embora menos eficaz, se comparado a um sistema que usa meio líquido para refrigeração/aquecimento.

Além disso, também foi demonstrada a necessidade em manter temperaturas de maneira uniforme entre $20^{\circ} \mathrm{C}$ a $40^{\circ} \mathrm{C}$ com variação máxima de $5 \mathrm{~K}$, visando aumentar sua vida útil, melhorar desempenho e nível de segurança. 
Com isso, foram descritos diferentes sistemas de refrigeração da bateria com diferentes níveis de complexidade que utilizam como meio de refrigeração/aquecimento o ar ou a água.

Analisando os resultados encontrados na tabela 1, observa-se que os sistemas que utilizam somente ar receberam menores notas pelo fato de serem menos eficientes e possuírem reduzido nível de segurança quando comparados aos outros sistemas mais complexos. Por outro lado, pode-se constatar que os sistemas líquidos possuem maior eficiência e níveis de segurança, sendo os sistemas mais escolhidos para serem implementados nos carros atuais.

Conclui-se que o sistema líquido combinado possui alta flexibilidade de operação em temperaturas extremas, mantendo-a dentro da faixa de trabalho ideal. Além disso, apesar de possuir elevado consumo energético e maior peso, mostrou-se vantajoso em fatores de maior relevância, principalmente segurança e performance quando comparado a todos outros sistemas mostrados neste trabalho. 


\section{REFERÊNCIAS}

[1] Mahamud R., Park C., 2011. Reciprocating air flow for Li-ion battery thermal management to improve temperature uniformity. Journal of Power Sources [2] Hawkins T., Singh B., 2012. Majeau-Bettez G., Stromman A., Comparative Environmental Life Cycle Assessment of Conventional and Electric Vehicles. Journal of Industrial Ecology, Yale University

[3] McKinsey \& Company, Bloomberg. An Integrated Perspective on the Future of Mobility. 2016.

[4] International Energy Agency, Global EV Outlook 2016, Beyond one million electric cars. Clear Energy Ministerial, 2016.

[5] Tesla. Model S. Disponível em www.tesla.com/models. Acesso em: 29/05/2017.

[6] Rao Z., Wang S., Wu M., Lin Z., Li F.; Experimental Investigation on Thermal Management of Electric Vehicle Battery with Heat Pipe. Energy Conversion and Management, 2012.

[7] Electropaedia, 2017. Lithium Battery Failures. Disponível em: http://www.mpoweruk.com/chemistries.htm, Acesso em: 28.05.2017.

[8] Matthe, R., Turner, L. \& Mettlach, H., VOLTEC Battery System for Electric Vehicle with Extended Range. SAE International Journal of Engines, 4(1), pp. 1944-1962. 2011.

[9] Pesaran, A. A., Battery thermal models for hybrid vehicle simulations. Journal of power sources, Volume 110(2), p. 377-82. 2002.

[10] Heckenberger T.; Neumeister D.; Wiebelt A.; Herrmann H.; Fehrenbacher C.; Isermeyer T.; Li-ion Battery Cooling in Hybrid and Electric Cars - More than just another. Behr GmbH \& Co. KG, Stuttgart. Stuttgartner Symposium, 2009.

[11] Li J., ZHU Z., Battery Thermal Management Systems of Electric Vehicles. CHALMERS UNIVERSITY OF TECHNOLOGY, Department of Applied Mechanics, Sweden 2014. 